\title{
O FUNDEB E A DESIGUALDADE EDUCACIONAL NOS MUNICÍPIOS DO ESTADO DO PARANÁ
}

\author{
RAFAEL ENCINAS ${ }^{1}$ \\ Rogério Allon Duenhas ${ }^{2}$
}

\begin{abstract}
RESUMO: A Constituição Federal elege como um dos objetivos da República a redução das desigualdades sociais e regionais e a educação é uma das variáveis de maior poder explicativo para a desigualdade brasileira. Todavia, se o financiamento da educação básica nos estados e municípios reproduz as desigualdades existentes, dificilmente tal conjuntura será alterada. Diante do fim da vigência do Fundeb, em 2020, é oportuno que o país discuta em que medida um novo fundo deva considerar critérios de redução da desigualdade social e educacional. Neste trabalho, analisamos se o Fundeb é um instrumento de redução da desigualdade, tanto em termos regionais quanto dentro de um único estado da Federação, considerando o estudo de caso do Paraná.
\end{abstract}

Palavras-chave: Educação básica. Desigualdades educacionais. Fundeb. Financiamento da educação. Municípios do Paraná.

\section{FUNDEB AND EDUCATIONAL INEQUALITY IN MUNICIPALITIES IN THE STATE OF PARANÁ}

\begin{abstract}
Brazilian Federal Constitution elects as one of the objectives of the Republic the reduction of social and regional inequalities, and education is one of the variables with the greatest explanatory power for Brazilian inequality. However, if the financing of basic education in the states and municipalities reproduces the existing inequalities, this conjuncture will hardly be changed. Considering the end of the validity of Fundeb, in 2020, it is opportune that the country discusses to what extent a new fund should consider criteria for reducing social and educational inequality. It is analyzed, in this paper, whether Fundeb is a tool for the reduction of inequality, both in regional terms and within a single state of the Federation, considering the case study of Paraná.
\end{abstract}

Keywords: Basic education. Educational inequalities. Fundeb. Education financing. Municipalities of Paraná.

1.Universidade Tecnológica Federal do Paraná - Departamento de Gestão e Economia - Curitiba (PR), Brasil. E-mail: encinas@alunos.utfpr.edu.br

2.Universidade Tecnológica Federal do Paraná - Departamento de Gestão e Economia - Curitiba (PR), Brasil. E-mail: rogerioduenhas@utfpr.edu.br 


\section{FUNDEB Y LA DESIGUALDAD EDUCATIVA EN LOS MUNICIPIOS DEL ESTADO DE PARANÁ}

RESUMEN: La Constitución Federal elige como un de los objetivos de la República la reducción de las desigualdades sociales y la educación es una das variables de mayor poder explicativo para la desigualdad brasilera. Sin embargo, se la financiación de la educación básica en los estados e municipios reproduce las desigualdades existentes, difícilmente tal coyuntura será alterada. Frente al fin de la vigencia de Fundeb, en 2020, es oportuno que el país discuta en qué medida un nuevo fundo deba considerar criterios de reducción de las desigualdades social y educativa. En esto artículo, se analiza se Fundeb es una herramienta de reducción de la desigualdad, tanto regionalmente cuanto dentro de un único estado de la Federación, considerando el estudio del caso de Paraná.

Palabras-clave: Educación básica. Desigualdades educativas. Fundeb. Financiación de la educación. Municipios de Paraná.

\section{Introdução}

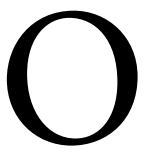

Brasil é considerado um dos países mais desiguais do mundo (PNUD, 2016, p. 206-209). A classificação é dada a partir do Índice de Gini, que avalia a desigualdade de renda. Tal desigualdade, porém, influencia diretamente desigualdades em outras dimensões do bem-estar e vice-versa (PNUD, 2016, p. 80). Em geral, as variáveis que avaliam o desempenho educacional revelam, com bastante acuidade, os padrões de desigualdade verificados em desagregações de grupos populacionais por renda. Pressupõe-se que diferentes oportunidades de acesso à educação resultem em diferentes níveis de renda, bem como que desigualdades de renda resultem em desigualdade no nível educacional.

A Constituição Federal de 1988 (CF88) promoveu uma ampla descentralização das políticas sociais, transferindo competências para os entes municipais. Todavia, se, por um lado, a descentralização permite que o planejamento esteja mais próximo da realidade local e que as comunidades municipais possam participar das decisões e fiscalizar seus governantes de maneira mais efetiva, por outro, pode ampliar as desigualdades, em virtude das diferenças nas capacidades econômica e administrativa dos municípios, sendo necessária uma atuação coordenadora do ente central.

Foram instituídos alguns instrumentos com o objetivo de reduzir as desigualdades sociais e garantir a aplicação de recursos mínimos na educação, entre os quais o Fundo de Manutenção e Desenvolvimento da Educação Básica e de Valorização dos Profissionais da Educação (Fundeb), que visa garantir o financiamento da educação básica pelos entes governamentais.

Entretanto, o Fundeb apresenta distorções na forma como são arrecadados e distribuídos os recursos entre os municípios em alguns estados. Em nível regional, a complementação da União garante um valor mínimo anual por aluno para os estados, mas a distância no financiamento da educação entre as unidades da Federação ainda se mantém significativa. Já em nível estadual, dependendo da unidade da Federação, o fundo atua como um "Robin Hood" às avessas, retirando recursos dos municípios menores e distribuindo para os maiores. O Fundeb não possui critérios que permitam a redução das desigualdades entre os municípios de um mesmo estado, fazendo com que aqueles com piores indicadores em educação apresentem saldo negativo entre os valores pago e recebido do fundo. 
A discussão acerca dessas distorções mostra-se oportuna, tendo em vista o fim da vigência do Fundeb, prevista para 2020, e a possibilidade de instituição de um novo fundo que permita uma redução das desigualdades educacionais.

\section{Federalismo e Políticas Educacionais}

A educação é definida pela CF88, em seu art. $6^{\circ}$, como direito social. Por conseguinte, é dever do Estado provê-la. O art. 205 define esse dever de maneira explícita e o art. 208 estabelece a educação como direito subjetivo, importando a responsabilidade da autoridade competente em caso de não oferecimento ou oferta irregular do ensino obrigatório. Já o art. 206 estabelece os princípios do ensino a ser ministrado, cujo primeiro é o de igualdade de condições para acesso e permanência na escola. Contudo, o que se observa é que a desigualdade ainda é elevada no país, tanto em termos sociais quanto educacionais.

No Brasil, a desigualdade se dá principalmente em nível regional. Enquanto o Índice de Desenvolvimento Humano Municipal (IDHM) médio das regiões Norte e Nordeste é de 0,667 e 0,663, respectivamente, Sudeste, Centro-Oeste e Sul apresentam índice, respectivamente, de 0,766, 0,757 e 0,754. Isso, porém, não significa que também não existam desigualdades entre os municípios de um mesmo estado. O IDHM, no Paraná, por exemplo, varia entre 0,546 e 0,843.

Essa mesma desigualdade pode ser observada nos indicadores da educação. $O$ Índice de Desenvolvimento da Educação Básica (Ideb) foi instituído pelo Decreto n. 6.094/2007 como instrumento para a avaliação da qualidade da educação básica por meio da combinação de dados de rendimento escolar e do desempenho dos alunos.

Esse índice é um indicador de qualidade educacional que combina informações do desempenho, em exames padronizados (Prova Brasil ou Saeb), obtido pelos estudantes ao fim das etapas de ensino ( $5^{\circ}$ e $9^{\circ}$ anos do Ensino Fundamental e $3^{\circ}$ ano do Ensino Médio), com informações sobre o rendimento escolar (aprovação).

Uma das críticas relacionadas a exames padronizados como o Ideb é que não avaliariam adequadamente o trabalho das escolas para proporcionar aprendizado aos alunos. "Uma escola que recebe alunos carentes, com escassa bagagem cultural, pode realizar um excelente trabalho e, ainda assim, não ter seus alunos entre aqueles com melhores resultados" (FERNANDES; GREMAUD, 2009, p. 3). Por conseguinte, os exames padronizados não apontam, necessariamente, o desempenho da gestão municipal na educação: eles também são influenciados pelas condições externas que impactam no desempenho dos estudantes.

No entanto, atualmente, o Ideb é a medida mais objetiva para avaliar a qualidade da educação básica, além de permitir acompanhar o cumprimento de metas fixadas nos planos nacionais, bem como comparar o desempenho entre as diversas redes de ensino. No Paraná, o Ideb dos anos iniciais varia entre 3,8 e 8,1.

Diante desse contexto de amplas desigualdades social e educacional, num país com dimensões continentais e diversidade cultural como o Brasil, a atuação efetiva do poder público mostra-se vital. Entretanto, alguns fatores tornam a ação estatal mais complexa, sendo um dos principais o federalismo brasileiro, em que existem três esferas de governo com responsabilidades sobre as mesmas políticas.

A CF88 define como competência comum entre União, estados e municípios prover os meios de acesso à educação, pelo que a coordenação entre tais entes se torna fator primordial para a redução das desigualdades. Ao estabelecer que os municípios atuem, prioritariamente, no Ensino Fundamental e na educação infantil e os estados nos Ensinos Fundamental e Médio, a CF88 visa à descentralização da política educacional, conferindo responsabilidades maiores aos entes mais próximos da realidade local, ao mesmo tempo que os coloca como corresponsáveis por etapas do ciclo educacional. 
A descentralização das políticas sociais apresenta vantagens e desvantagens na gestão das políticas públicas. Por um lado, a descentralização permite que o tomador de decisão seja aquele com maior conhecimento da realidade local e facilita o controle e a participação da sociedade, além de permitir maior inovação nas políticas públicas e no enfrentamento de problemas. Segundo Nascimento e Souza,

[...] observa-se que, geralmente, as políticas de desenvolvimento são propostas pelo Estado central. Entretanto, constata-se que a idealização dessas políticas sofre com vieses ideológicopartidários e sua implementação nem sempre alcança os resultados esperados. Visto isso, Polèse [...] questiona com pertinência: por que não se promover o desenvolvimento das regiões a partir das próprias dinâmicas locais? O desenvolvimento local - também denominado de "endógeno", "de baixo para cima" ou "comunitário" - exprime a esperança de que o próprio ambiente local (milieu) possa iniciar e conduzir seu processo de desenvolvimento, um desenvolvimento local baseado nas iniciativas e savoir-faire dos atores locais, que são os indivíduos e as organizações (NASCIMENTO; SOUZA, 2004, p. 181).

Quando as especificidades locais são levadas em consideração, não apenas o planejamento e a formulação das políticas públicas passam a refletir de maneira coerente as necessidades de um determinado território, mas também a avaliação de seu resultado passa a fornecer "informações valiosas para eventuais ajustes e flexibilizações institucionais que permitam uma melhor focalização e, consequentemente, mais efetividade na ação governamental" (SILVA, 2013). Portanto, levar em consideração aspectos locais é essencial para a efetividade das políticas públicas.

Por outro lado, a descentralização agrava as desigualdades sociais, na medida em que as localidades com maior capacidade financeira e de gestão tendem a aumentar ainda mais a distância para as localidades mais pobres. Segundo Abrucio,

[...] supondo que um país resolva seus dilemas básicos de ordem e haja um sentimento nacional razoavelmente consolidado, é preciso evitar o crescimento das desigualdades entre as regiões. Algumas experiências recentes de descentralização não foram acompanhadas pela criação de políticas redistributivas - ou ao menos compensatórias - para as localidades mais pobres ou carentes de infraestrutura, o que contribuiu para acentuar as diferenças socioeconômicas. Nestes casos, a descentralização torna-se, na precisa definição de Remy Prud'Homme, "na mãe da segregação" [...], uma vez que as disparidades entre as partes prejudicam o desenvolvimento de muitas delas e, ao fim e ao cabo, do próprio conjunto, pois há uma piora do desempenho econômico global, um aumento do conflito distributivo e, no extremo, a luta política assume proporções preocupantes à ordem nacional. Os impactos desse processo negativo são ainda maiores em grandes nações marcadas pela desigualdade regional, como a Índia, o Brasil e a Rússia. Para solucionar este problema, faz-se necessária a atuação coordenadora do governo central, sem a qual não é possível uma descentralização efetiva e justa (ABRUCIO, 2002, p. 154).

Para Abrucio (2005), cinco são as questões que colocam obstáculos ao bom desempenho dos municípios do país: a desigualdade econômica e administrativa; o discurso do "municipalismo autárquico"; a "metropolização" acelerada; os resquícios ainda existentes tanto de uma cultura política quanto de instituições que dificultam a accountability democrática; e o padrão de relações intergovernamentais.

O municipalismo autárquico prega que os governos locais poderiam, sozinhos, resolver todos os dilemas de ação coletiva colocados às suas populações. Essa visão incentiva a "prefeiturização", em que cada 
prefeito defenderia seu município "como uma unidade legítima e separada das demais, o que é uma miopia em relação aos problemas comuns em termos micro- e macrorregionais" (ABRUCIO, 2005, p. 48).

Em um contexto de desigualdade social, a presença de um ator central é importante. Para Arretche (2004, p. 20), “a coordenação federal dos programas sociais se justifica tanto por razões relacionadas à coordenação das decisões dos governos locais quanto para corrigir desigualdades de capacidade de gasto entre estados e municípios". Segundo a autora,

[...] com exceção da política de educação fundamental, a concentração de autoridade no Governo Federal caracteriza as relações federativas na gestão das políticas, pois à União cabe o papel de principal financiador, bem como de normatização e coordenação das relações intergovernamentais (ARRETCHE, 2004, p. 20).

O formato de gestão que concentra autoridade no Governo Federal apresenta vantagens para a coordenação dos objetivos das políticas no território nacional, pois permite reduzir o risco de que os diferentes níveis de governo imponham conflitos entre programas e elevação dos custos da implementação, cuja ocorrência é mais provável em estados federativos [...]. Além disso, a concentração do financiamento no Governo Federal permitiria alcançar resultados redistributivos [...] (ARRETCHE, 2004, p. 24).

A educação fundamental é, portanto, exceção entre as políticas sociais no tocante à atuação coordenadora do Governo Federal, o que se reflete em termos de desigualdades de capacidade de gasto das unidades da Federação, implicando diferenças na carreira e nos salários dos professores, bem como na natureza e na qualidade dos serviços educacionais. Segundo Arretche,

[...] a arrecadação de tributos é extremamente desigual no plano horizontal, isto é, entre os governos subnacionais. A razão entre os estados com maior e menor capacidade de arrecadação tributária própria em 1997 foi de 9,4 [...]. No interior de cada estado, municípios de mesmo tamanho apresentam enorme diversidade de arrecadação. Excetuando-se as capitais - com arrecadação até dez vezes superior à dos demais municípios de seu próprio estado -, os municípios de maior porte não revelam melhor desempenho do que os pequenos, independentemente do nível de renda do estado em que estão localizados (ARRETCHE, 2004, p. 18).

Segundo Akkari (2001), a fragmentação do sistema educacional brasileiro é alimentada por três fatores: a privatização neoliberal; o pacto das elites; e a descentralização. Essa última constituiria um fator para que a transferência de responsabilidades pela CF88 não tenha sido "acompanhada por um dispositivo de apoios financeiro, técnico e pedagógico suficientes” (AKKARI, 2001, p. 176). O autor ainda afirma que as enormes disparidades, em termos de financiamento da educação básica no Brasil, têm origem na descentralização que reforça a desigualdade entre estados, comunidades e regiões.

O modelo de política educacional proposto pela CF88, na visão de Abrucio, tem como uma de suas características "a adoção de elementos matizadores de uma descentralização centrífuga, que seria prejudicial a um país tão desigual” (2010, p. 60). Os fundos de financiamento da educação como, o antigo Fundef e o Fundeb, tiveram bons resultados na promoção de maior municipalização do Ensino Fundamental e no aumento da cobertura do sistema. Todavia, segundo Abrucio, 
[...] o sucesso desses fundos federativos não pode esconder os problemas que ainda persistem no plano intergovernamental. Em primeiro lugar, eles conseguiram dar mais recursos aos governos que se responsabilizam pela política, mas mexeram pouco com as desigualdades regionais que marcam a Federação brasileira. Para tanto, seria necessário que a União não só complementasse o dinheiro que falta para chegar à meta básica, mas que também fizesse política redistributiva. Caso contrário, a equalização se dá num patamar mínimo, e as redes dos estados mais ricos tendem a ter uma diferença substancial de condições em relação aos demais (ABRUCIO, 2010, p. 64).

O Fundeb é um dos instrumentos mais importantes da coordenação da política de educação básica pelo governo central, pois define regras para aplicação mínima de recursos na educação e na valorização dos profissionais. Como instrumento de coordenação da política, deveria possuir critérios voltados para a redução da desigualdade educacional.

A CF88 elege como um dos objetivos da República a redução das desigualdades sociais e regionais (art. $3^{\circ}$, inciso III) e estabelece que os orçamentos fiscal e de investimento das empresas das quais a União seja sócia majoritária tenham entre suas funções a redução das desigualdades inter-regionais (art. 165, \$7º). Mais especificamente, no que se refere à educação, a CF88 estabelece como seu primeiro princípio a "igualdade de condições para o acesso e a permanência na escola” (art. 206, inciso I). Por conseguinte, é fundamental que instrumentos como o Fundeb tenham entre seus objetivos as reduções das desigualdades, tanto regionais quanto dentro de um único estado.

\section{O Fundeb e as Desigualdades Sociais e Educacionais}

Com o objetivo de garantir o direito fundamental à educação, a CF88 estabelece, em seu artigo 212, percentuais mínimos da arrecadação de impostos que os três níveis da Federação devem aplicar na manutenção e no desenvolvimento do ensino. Além disso, o artigo 60 do Ato das Disposições Constitucionais Transitórias (ADCT) define que parte desse percentual mínimo deva ser destinada à manutenção e ao desenvolvimento da educação básica e à remuneração condigna dos trabalhadores da educação, sendo que a distribuição dos recursos e de responsabilidades entre os estados e seus municípios será assegurada mediante a criação do Fundeb.

O Fundeb foi regulamentado pela Lei n. 11.494/2007, com vigência estabelecida para o período entre 2007 e 2020. Trata-se de fundo especial, de natureza contábil e de âmbito estadual, formado por parcela financeira de recursos federais e por recursos provenientes dos impostos e transferências dos estados e municípios. A União ainda contribui, a título de complementação financeira, com o objetivo de assegurar o valor mínimo nacional por aluno/ano a cada estado em que tal limite mínimo não tenha sido alcançado com recursos dos próprios governos.

O Fundeb em cada estado é composto por $20 \%$ da arrecadação de impostos dos estados e dos municípios, além de valores transferidos pela União mediante o Fundo de Participação dos Estados e do Distrito Federal (FPE) e o Fundo de Participação dos Municípios (FPM) (Lei n. 11.494/2007, art. 3º).

A princípio, verifica-se que, na arrecadação dos recursos, não há critérios voltados para a redução das desigualdades regionais, tendo em vista que estados mais desenvolvidos economicamente e com maior arrecadação possuirão um valor per capita maior do Fundeb. Por exemplo, em 2015, o valor per capita das receitas que compuseram o Fundeb do Rio Grande do Sul foi de R \$3.824,87, enquanto, no Maranhão, foi de R\$ 1.473,56. Entretanto, essa desigualdade é reduzida, pois o valor do Maranhão não alcançou o valor mínimo definido 
nacionalmente, conforme estabelece o inciso V do art. 60 do ADCT da CF88, que, em 2015, era de R\$2.545,31 (BRASIL, 2015). Dessa feita, o valor per capita do Fundeb no Maranhão, em 2015, com a complementação da União, foi de R \$2.854,70, ainda significativamente inferior, porém, ao valor do Rio Grande do Sul. Assim, verifica-se que, apesar de a complementação da União contribuir para os estados de menor arrecadação, ainda assim é significativa a desigualdade na composição dos recursos do Fundeb entre os estados da Federação.

Araújo (2012) analisou a desigualdade no financiamento da educação entre estados brasileiros, identificando que, por exemplo, alunos matriculados em São Paulo em creche, pré-escola e Ensino Fundamental recebem, respectivamente, 3,53, 3,61 e 1,81 vezes a mais do que os alunos matriculados nos mesmos níveis no Ceará. Segundo Araújo,

[...] Assim, estados das regiões com menor capacidade de geração de recursos próprios ou de outras fontes adicionais de financiamento educacional conviverão com valores inferiores por aluno. A possibilidade de redução desta desigualdade, que está ancorada no perfil do desenvolvimento regional e na distribuição dos recursos tributários no país, repousará na capacidade da política redistributiva (neste caso, o Fundeb) de minimizar seus efeitos (ARAÚJO, 2012, p. 1224).

Do outro lado, a distribuição dos recursos que compõem o fundo é realizada com base no número de alunos da educação básica pública, de acordo com dados do último censo escolar, sendo que os municípios recebem os recursos do Fundeb com base no número de alunos da educação infantil e do Ensino Médio e os estados, com base no número de alunos dos Ensinos Fundamental e Médio.

Um dos problemas relacionados ao fundo é o critério para distribuição dos recursos entre os municípios do estado pela quantidade de alunos, sem considerar questões distributivas. Utiliza-se como critério apenas o quantitativo de alunos, o que pode levar a distorções na distribuição dos recursos.

Para avaliar se o Fundeb promove distorções no financiamento da educação básica dos municípios, foi realizado estudo de caso no estado do Paraná. Buscou-se verificar se o fundo privilegia algum tipo de município de acordo com seu tamanho ou nota no Ideb. Foram comparados a contribuição de cada município para o fundo e o valor dele recebido. Foram, também, realizadas análises da correlação ${ }^{1}$ do valor líquido do fundo (valor recebido menos o contribuído) com a população dos municípios e o Ideb.

Para o cálculo da correlação, optou-se pela utilização do coeficiente de correlação de postos de Spearman². O método mais tradicional, de Pearson, pressupõe a distribuição normal das variáveis, enquanto o de Spearman é um método não paramétrico ${ }^{3}$; ou seja, não faz suposições sobre a distribuição de frequências das variáveis. Foi aplicado às variáveis o teste de normalidade Shapiro-Wilk ${ }^{4}$ e nenhuma apresentou distribuição normal.

Para a interpretação dos coeficientes de correlação, foi utilizada a classificação de intensidade proposta por Rowntree (1981, p. 170), descrita na Tabela 1. Os coeficientes de correlação foram calculados na linguagem de programação estatística R, por meio da função cor.test(), do pacote stats, utilizando-se o método de Spearman.

Tabela 1. Classificação da intensidade da correlação (números absolutos).

\begin{tabular}{cc}
\hline Coeficiente $+\mathbf{o u}-$ & Intensidade \\
\hline Entre 0,00 e 0,20 & Muito fraca, desprezível \\
\hline Entre 0,20 e 0,40 & Fraca \\
\hline Entre 0,40 e 0,70 & Moderada \\
\hline Entre 0,70 e 0,90 & Forte \\
\hline Entre 0,90 e 1,00 & Muito forte \\
\hline
\end{tabular}

Fonte: Rowntree (1981, p. 170). 
Os dados relativos ao Fundeb e das despesas com educação foram obtidos junto à Declaração de Contas Anuais do Sistema de Informações Contábeis e Fiscais do Setor Público Brasileiro (Siconfi), da Secretaria do Tesouro Nacional (STN), e ao "Anexo III - Demonstrativo da Receita Corrente Líquida”, dos Relatórios Resumidos da Execução Orçamentária (RREO) dos municípios, disponíveis no Siconfi. A pesquisa sobre o estado do Paraná retornou dados para 371 municípios, tendo ele um total de 399. Para os municípios sem dados no Siconfi, foi feita pesquisa no portal do Tribunal de Contas do Estado do Paraná (TCE-PR). Foram selecionados os relativos ao exercício de 2015, pois nem todos os municípios possuíam dados para 2016 e 2017. Os dados relativos ao Ideb e ao número de alunos no Censo Escolar de 2015 foram consultados junto ao Instituto Nacional de Estudos e Pesquisas Educacionais Anísio Teixeira (Inep).

Para o cálculo do valor per capita, considerou-se a quantidade de alunos matriculados nos níveis infantil e fundamental da rede municipal, níveis esses considerados prioritários para os municípios no $\$ 2^{\circ}$ do art. 211 da CF88, o qual é também o critério utilizado na distribuição dos recursos do Fundeb. Dois municípios apresentaram valores muito distantes dos demais para o valor líquido por aluno do Fundeb e foram retirados da análise. Enquanto os valores dos demais municípios variam entre R\$ 6.906,00 e R\$3.309,00 - Bom Sucesso do Sul teve R \$11.802,00 e Saudade do Iguaçu, R $27.048,00$.

Tendo em vista que as variáveis possuem escalas diferentes - o Ideb varia entre 0 a 10 e o valor líquido do Fundeb pode ser negativo e alcançar milhares de reais -, recomenda-se a padronização, por meio da sua conversão em escores-padrão (também conhecidos como escores Z), pela subtração da média e a divisão pelo desvio-padrão para cada variável (HAIR et al., 2009).

Verificou-se que o Fundeb não promove a redução das desigualdades, uma vez que não privilegia os municípios de piores indicadores educacionais ou sociais. Em alguns casos, o Fundeb retira recursos de municípios que possuem indicadores ruins em educação. É o caso do município de pior Ideb do estado, Nossa Senhora das Graças, com 3,8 no Ideb 2015. O município recebeu quase R\$ 1,5 milhão do Fundeb em 2015, enquanto sua contribuição foi de $\mathrm{R} \$ 2,1$ milhões.

O que se verifica é que os municípios de maior população tendem a receber valores líquidos por aluno maiores do Fundeb - ou seja, recebem mais do que contribuem para a formação do fundo -, enquanto os municípios menores tendem a apresentar valor líquido negativo, pois recebem valor inferior ao que contribuem. A Fig. 1 apresenta a relação entre o valor líquido do Fundeb por aluno e a população, cujo valor foi transformado por meio de logaritmo para facilitar a visualização dos dados.

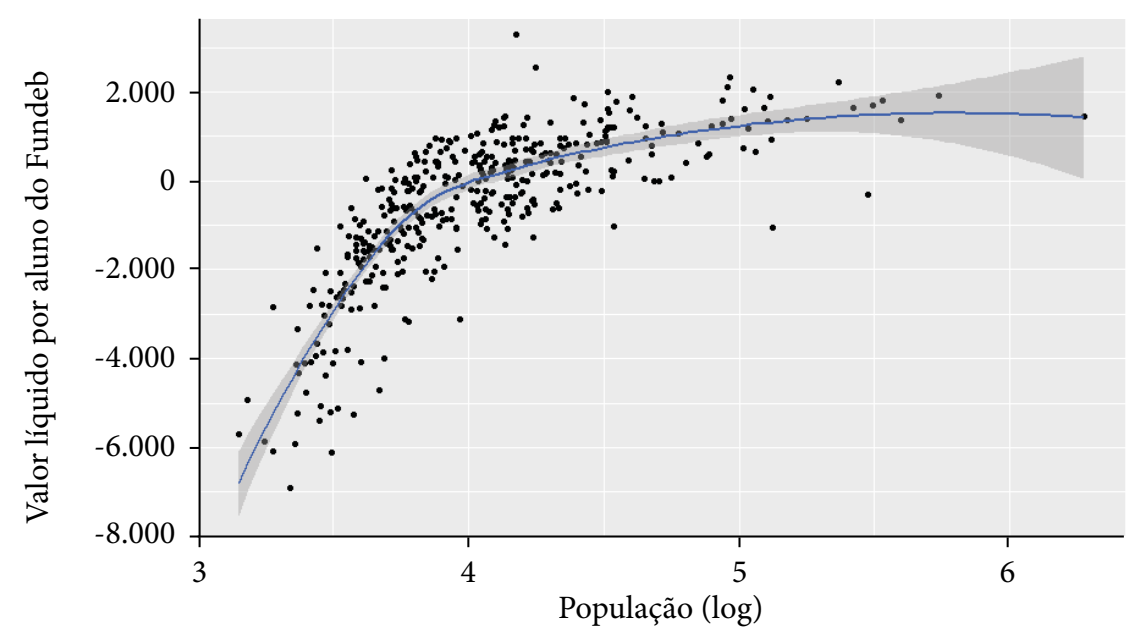

Fonte: Elaboração própria a partir da pesquisa.

Figura 1. Relação entre a população e o valor líquido por aluno do Fundeb em 2015. 
O que se observa é uma relação positiva entre as variáveis; ou seja, quanto maior o município, maior o valor líquido por aluno que ele recebe do Fundeb. Isso é confirmado pelo coeficiente de correlação. O valor líquido do Fundeb por aluno apresentou correlação de 0,8065 com a população dos municípios (valor-p de $\left.2.2 \mathrm{e}^{-16}\right)^{5}$ e de 0,8686 com a quantidade de alunos (valor-p de $2.2 \mathrm{e}^{-16}$ ). Portanto, o valor líquido do Fundeb mostra-se fortemente correlacionado com o tamanho do município.

Pinto (2007, p. 882) já apontava esse efeito "Robin Hood" às avessas no antigo Fundef, pois os municípios menores, principalmente situados nas regiões mais pobres, dependem mais do FPM. A CF88 determina que a União repasse parte de sua arrecadação de impostos para os municípios por meio do FPM. Os coeficientes individuais de participação dos municípios no FPM são mensurados com base na estimativa da população de cada município, calculada anualmente pelo IBGE, e na renda per capita do estado em que tal município se insere.

Pinto (2007) afirmava que o Fundeb aprofundaria ainda mais essa distorção, ao aumentar o percentual do FPM destinado ao fundo. Como 20\% do FPM é destinado para o Fundeb, os municípios menores contribuem com um valor maior em termos per capita. A Tabela 2 apresenta os valores líquidos total e por aluno dentro das faixas populacionais dos municípios do Paraná em 2015. Observa-se que os municípios com menos de 10.000 habitantes perderam mais de R 135 milhões com o Fundeb, uma perda por aluno de R\$ 128,93. Dos 94 municípios do estado com menos de 5.000 habitantes, 93 perdem recursos para o Fundeb.

Tabela 2. Valor líquido do Fundeb de acordo com a população dos municípios do estado do Paraná em 2015 (números absolutos).

\begin{tabular}{ccc}
\hline População & Valor líquido total (R\$) & Valor líquido por aluno (R\$) \\
\hline Até 10.000 & $(135.478 .262,88)$ & $(128,93)$ \\
\hline Entre 10.000 e 20.000 & $40.099 .332,44$ & 26,84 \\
\hline Entre 20.000 e 50.000 & $132.638 .444,63$ & 76,49 \\
\hline Entre 50.000 e 100.000 & $122.365 .668,38$ & 112,68 \\
\hline Mais de 100.000 & $605.636 .779,04$ & 104,59 \\
\hline
\end{tabular}

Fonte: Elaboração própria a partir da pesquisa.

Bremaeker (2011) apontou que a política de fundos enfraquece os municípios mais pobres, pois altera de modo negativo os critérios de repasse do FPM. O critério de repasse dos recursos do Fundeb considera somente o número de matrículas, enquanto o FPM distribui proporcionalmente mais recursos para os municípios com menor população. Como 20\% do FPM é destinado para o Fundeb, sua ação redistributiva é distorcida no momento em que o Fundeb redistribui os recursos pela quantidade de alunos.

Conte, ao analisar os impactos do Fundeb no Rio Grande do Sul, afirma que

[...] a tese que não se verifica no Rio Grande do Sul é a de que as transferências das receitas dos fundos contábeis de financiamento da educação para os municípios têm contribuído para redução das disparidades. A receita do fundo guarda relação direta com o tamanho do município e o seu produto interno bruto, sendo que os municípios e, consequentemente, regiões, que ganham recursos são os mais populosos e de melhores indicadores econômicos. Isso contribui para uma relação circular (ciclo vicioso) na ação pública, na qual o Estado está mais presente em poucos centros urbanos ou mesmo em algumas regiões. A ação estatal apenas reforça e reitera esta estrutura de desigualdade histórica. Os resultados corroboram a literatura 
que vem indicando que o Estado favorece e contribui para a continuidade das desigualdades regionais ou territoriais (sociais, econômicas etc.), por meio da distribuição do gasto público (receita) e dos investimentos no país (CONTE, 2018, p. 15).

Pinto também identificou problemas na comparação entre municípios da capital e do interior, pois esses dependeriam basicamente das transferências do Fundeb, além dos maiores custos relacionados à oferta da educação na zona rural, "o que tem levado ao fechamento de escolas e estimulado o transporte discente às instituições urbanas, com fortes prejuízos à qualidade do ensino” (2014).

Neste estudo, verificou-se que os municípios menores aplicam mais recursos por aluno nas subfunções da educação infantil e do Ensino Fundamental. A Fig. 2 apresenta a relação entre a população e os gastos dos municípios com as subfunções Ensino Fundamental e ensino infantil em 2015.

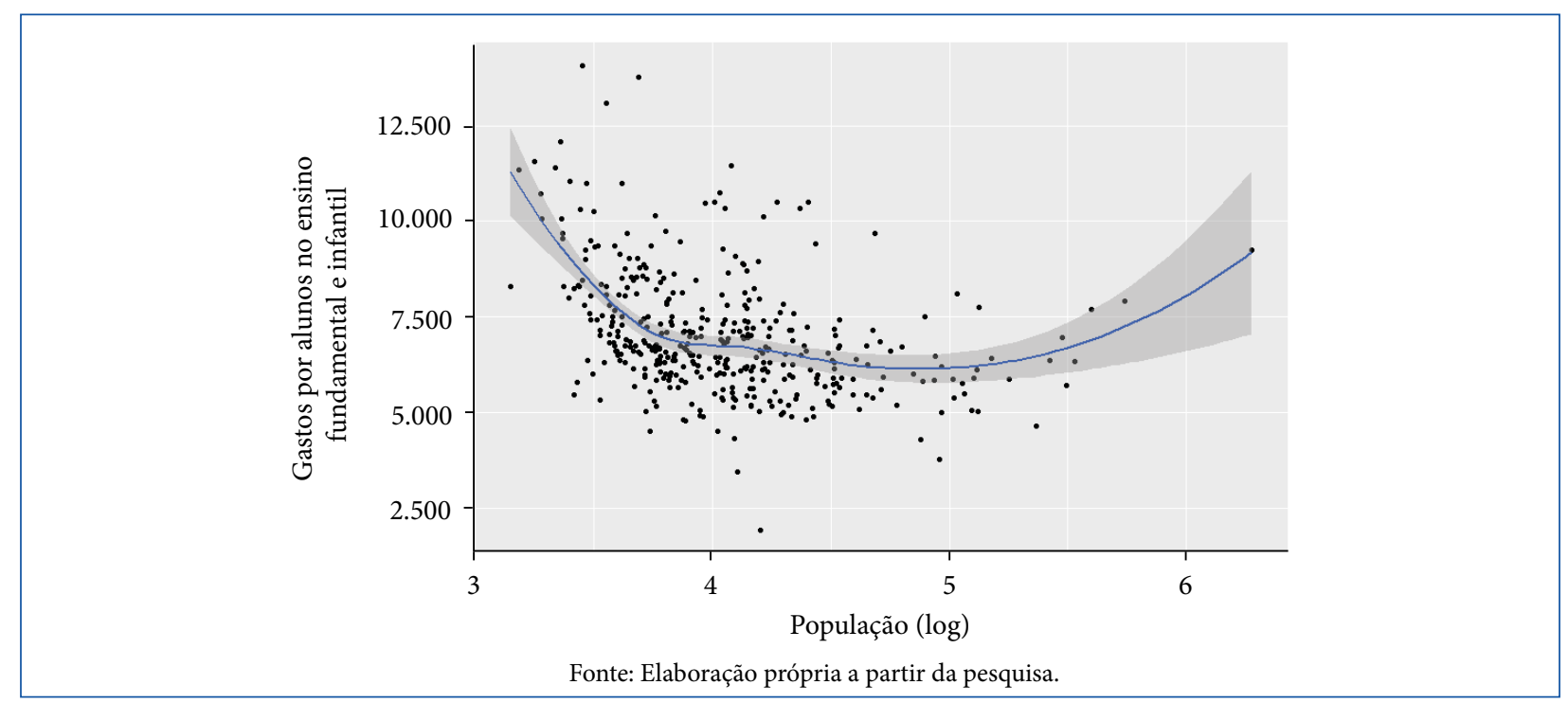

Figura 2. Relação entre a população e o gasto por aluno nas subfunções Ensino Fundamental e ensino infantil em 2015.

Observa-se que os municípios menores têm um gasto por aluno maior. O coeficiente de correlação de postos de Spearman entre a população e o gasto por aluno nas subfunções educação infantil e Ensino Fundamental é de $-0,4330$ (valor-p de $2.2 \mathrm{e}^{-16}$ ), o que demonstra a existência de uma correlação negativa moderada entre as duas variáveis, no sentido de que os municípios menores gastam um valor maior por aluno. Pela Tabela 3, observa-se a maior média do gasto por aluno nos municípios até 5.000 habitantes.

Tabela 3. Faixas populacionais e gasto por aluno na educação infantil e no Ensino Fundamental nos municípios do estado do Paraná em 2015.

\begin{tabular}{cc}
\hline Faixa Populacional & Média de gasto por aluno $(\mathbf{R} \mathbf{)}$ \\
\hline Até 5.000 & $8.262,99$ \\
\hline Entre 5.000 e 10.000 & $6.875,22$ \\
\hline Entre 10.000 e 20.000 & $6.744,24$ \\
\hline Entre 20.000 e 50.000 & $6.356,24$ \\
\hline Entre 50.000 e 100.000 & $5.860,92$ \\
\hline Mais de 100.000 & $6.386,09$
\end{tabular}

Fonte: Elaboração própria a partir da pesquisa. 
Contudo, esse gasto maior dos municípios menores não se reflete na qualidade do ensino. A Fig. 3 apresenta a relação entre população e Ideb. A correlação de Spearman entre a população e o Ideb é de 0,1572, com valor-p de 0,0018; ou seja, apesar de ser significante a ponto de rejeitar a hipótese de correlação nula, a intensidade da correlação é desprezível.

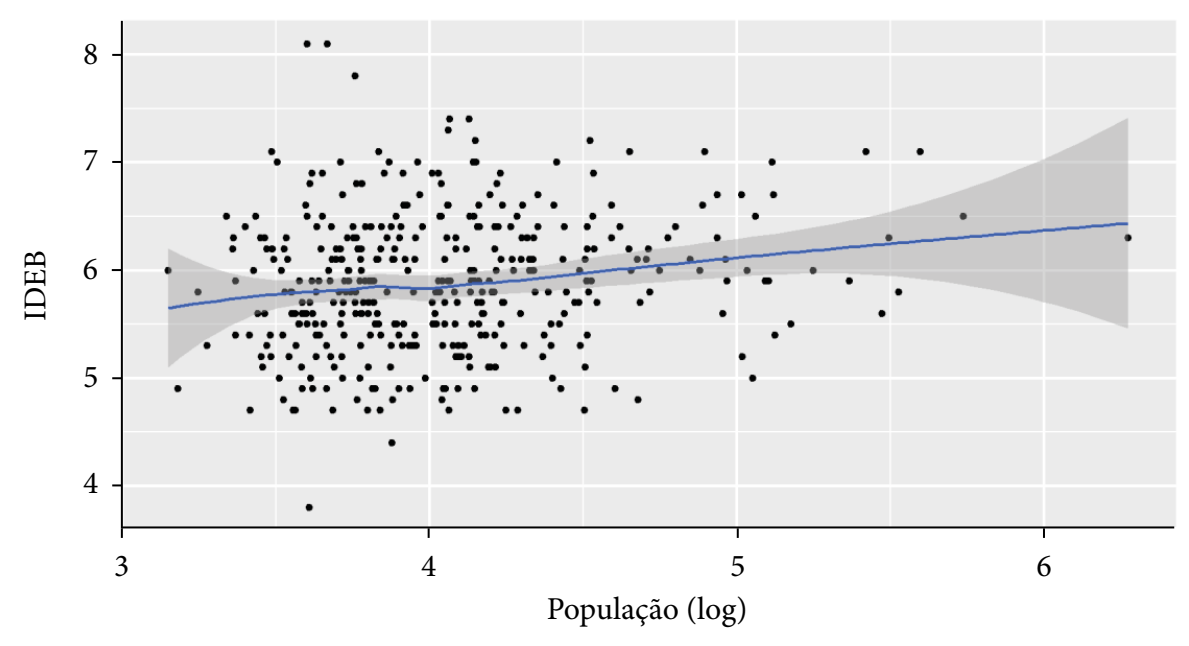

Fonte: Elaboração própria a partir da pesquisa.

Figura 3. Relação entre população e Ideb de 2015.

O fato de os municípios pequenos gastarem mais por aluno e não apresentarem resultados melhores pode significar um problema de ineficiência decorrente da falta de escala, o que necessitaria de investigações complementares. A média do número de alunos nos municípios de até 5.000 habitantes é de 377, com desviopadrão de 96. A partir dos dados, supõe-se que os municípios menores necessitem de um investimento maior em termos per capita, em virtude da ineficiência de escala, mas sejam os que possuem as maiores perdas quando se considera o valor líquido do Fundeb.

É complexa uma solução para a correção dos problemas redistributivos por um outro fundo que venha a substituir o Fundeb, principalmente quanto ao prejuízo aos municípios pequenos, graças ao desenho do FPM. Segundo Mendes et al.,

[...] no que diz respeito aos critérios de redistribuição regional de recursos fiscais (entre regiões e entre municípios), o FPM deixa muito a desejar. Conforme descrito [...], o critério população predomina como fator de repartição dos recursos do fundo. O uso dessa variável está malequacionado, havendo um forte viés em favor dos municípios menos populosos, conforme ilustrado no Gráfico III.1, que mostra a queda abrupta da receita per capita de FPM à medida que aumenta a população municipal. [...] Esse privilégio aos municípios pequenos reduz a capacidade do FPM de direcionar recursos para os municípios menos desenvolvidos (MENDES, 2008, p. 35).

Na medida em que os municípios pequenos recebem um valor per capita superior do FPM, sua contribuição ao Fundeb será maior, resultando numa perda líquida de recursos. Por conseguinte, é necessário que as desigualdades social e educacional passem a constituir critério de distribuição de recursos tanto do FPM quanto de um fundo que venha a substituir o Fundeb. 


\section{Considerações Finais}

A educação possui importância crucial para a redução das desigualdades sociais. A desigualdade tanto influencia os níveis educacionais quanto é influenciada por eles. Diferentes oportunidades de acesso à educação resultam em diferentes níveis de renda, influência que também ocorre no sentido inverso.

A descentralização das políticas sociais, apesar das vantagens em termos de planejamento e controle sociais, pode ampliar as desigualdades, tendo em vista as diferentes capacidades financeiras e administrativas dos municípios. Cabe ao governo central exercer o papel de coordenação e buscar amenizar os desequilíbrios. Entre os instrumentos mais importantes de coordenação da política de educação básica está o Fundeb.

O Fundeb contribui para a redução das desigualdades regionais, principalmente estabelecendo um valor mínimo nacional por aluno com complementação da União para os estados em que tal valor não é alcançado. Todavia, ainda assim, essa distância mostra-se significativa, uma vez que os estados de maior capacidade arrecadatória aplicam valor significativamente superior ao mínimo nacional.

Por outro lado, observa-se uma distorção significativa na composição e na distribuição dos recursos do Fundeb dentro do estado Paraná, pois o fundo retira recursos dos municípios pequenos e os entrega aos grandes, o que é provável que também esteja ocorrendo em outras unidades da Federação. Verificou-se que há uma forte correlação entre o valor líquido do Fundeb por aluno e o tamanho da população dos municípios; ou seja, os municípios pequenos tendem a contribuir com um valor maior em relação ao que recebem do fundo, enquanto o valor líquido por aluno dos municípios grandes é maior. Isso tende a se mostrar ainda mais deletério, pois se verifica que os municípios menores aplicam um valor maior por aluno na educação básica. Esse investimento maior não se reflete em indicadores melhores de qualidade da educação, demonstrando uma possível ineficiência de escala. Além disso, não há nenhum critério que considere a desigualdade de renda ou educacional entre os municípios: todos recebem o mesmo valor a partir do número de alunos.

Diante desse contexto, e com a proximidade do fim da vigência do Fundeb, em 2020, é importante que o país repense os critérios de arrecadação e distribuição de recursos na educação, de modo a reduzir as desigualdades sociais e educacionais.

\section{Contribuição dos Autores}

Problematização e Conceitualização: Encinas, R.; Duenhas, R.A.; Metodologia: Encinas, R.; Duenhas, R.A.; Análise: Encinas, R.; Duenhas, R.A.; Redação: Encinas, R.; Duenhas, R.A.

\section{Notas}

1. A análise de correlação mede a intensidade e a direção do relacionamento entre duas variáveis, sem identificar a existência de causalidade - apenas se elas variam conjuntamente em alguma medida.

2. A correlação de Pearson avalia a relação linear entre duas variáveis contínuas. Uma relação é linear quando a mudança em uma variável é associada a uma mudança proporcional na outra. A correlação de Spearman avalia a relação monotônica entre duas variáveis contínuas ou ordinais. Em uma relação monotônica, as variáveis tendem a mudar juntas, mas não necessariamente a uma taxa constante. O coeficiente de correlação de Spearman baseia-se nos valores classificados de cada variável em vez de se basear nos dados brutos.

3. Os testes paramétricos incidem sobre parâmetros de duas ou mais populações, como a média e o desvio-padrão, e pressupõem uma forma particular e conhecida das distribuições populacionais das quais as amostras foram recolhidas (p. ex., normal, binomial). Os testes não paramétricos não pressupõem qualquer forma para a distribuição de probabilidades dos dados em análise. 
4. O teste de Shapiro-Wilk testa a normalidade na estatística frequentista. Proposto em 1965, calcula uma estatística W, que testa se uma amostra aleatória de tamanho n provém de uma distribuição normal.

5. O valor-p é chamado também de nível descritivo ou probabilidade de significância. Ele corresponde à probabilidade de se obter uma estatística de teste igual ou mais extrema que aquela observada em uma amostra, sob a hipótese nula. Comumente, em testes de hipótese, pode-se rejeitar a hipótese nula caso o valor-p seja menor que 5\%. Em termos gerais, um valor-p pequeno significa que a probabilidade de obter um valor da estatística de teste como o observado é muito improvável, levando, assim, à rejeição da hipótese nula. No caso da correlação, a hipótese nula é que as variáveis não possuam correlação; com valor-p inferior a $5 \%$ ela pode ser rejeitada, aceitando-se a existência de correlação.

\section{Referências}

ABRUCIO, F. L. Descentralização e coordenação federativa no Brasil: Lições dos anos FHC. In: ABRUCIO, F. L.; LOUREIRO, M. R. G. (orgs.). O Estado numa era de reformas: Os anos FHC - parte 2. Brasília: MP/ SEGES, 2002.

ABRUCIO, F. L. A coordenação federativa no Brasil: A experiência do período FHC e os desafios do governo Lula. Revista de Sociologia e Política, Curitiba, n. 24, p. 41-67, 2005. https://doi.org/10.1590/ S0104-44782005000100005

ABRUCIO, F. L. A dinâmica federativa da educação brasileira: Diagnóstico e propostas de aperfeiçoamento. In: OLIVEIRA, R. P.; SANTANA, W. (orgs.). Educação e federalismo no Brasil: Combater as desigualdades, garantir a diversidade. Brasília: Unesco, 2010. Disponível em: https://unesdoc.unesco.org/ark:/48223/ pf0000187336. Acesso em: 18 set. 2018.

AKKARI, A. J. Desigualdades educativas estruturais no Brasil: Entre estado, privatização e descentralização. Educação \& Sociedade, Campinas, v. 22, n. 74, p. 163-189, 2001. http://doi.org/10.1590/ S0101-73302001000100010

ARAUJO, R. Desvendando o perfil dos gastos educacionais dos municípios brasileiros. Educação \& Sociedade, Campinas, v. 33, n. 121, p. 1215-1233, 2002. http://doi.org/10.1590/S0101-73302012000400016

ARRETCHE, M. Federalismo e políticas sociais no Brasil: Problemas de coordenação e autonomia. São Paulo em Perspectiva, São Paulo, v. 18, n. 2, p. 17-26, 2004. https://doi.org/10.1590/S0102-88392004000200003

BRASIL. Constituição da República Federativa do Brasil. Brasília: Diário Oficial da União, 5 out. 1988.

BRASIL. Ministério da Educação. Ministério da Fazenda. Portaria Interministerial n. 8, de 5 de novembro de 2015, Dispõe sobre o valor anual mínimo nacional por aluno. Diário Oficial da União, Brasília, DF, 6 nov. 2015.

BREMAEKER, F. E. J. A política de fundos para a educação e o impacto nas finanças dos estados e municípios. In: GOUVEIA, A. B.; PINTO, J. M. R.; CORBUCCI, P. R. (orgs.). Federalismo e políticas educacionais na efetivação do direito à educação no Brasil. Brasília: Ipea, 2011, p. 51-68. Disponível em: https://www.ipea. gov.br/portal/index.php?option=com_content\&amp;view=article\&amp;id=12318. Acesso em: 20 set. 2018.

CONTE, N. C. A política de fundos (Fundef/Fundeb) e suas disparidades no financiamento da educação básica no estado do Rio Grande do Sul. Fineduca, v. 8, n. 4, p. 1-18, 2018. https://doi.org/10.17648/ fineduca-2236-5907-v8-78205

FERNANDES, R.; GREMAUD, A. Avaliação da qualidade da educação no Brasil. São Paulo: Moderna, 2009. 
HAIR JR., J. F. et al. Análise multivariada de dados. 6. ed. Porto Alegre: Bookman, 2009.

MENDES, M. et al. Transferências intergovernamentais no Brasil: Diagnóstico e proposta de reforma. Texto para discussão n. 40. Brasília: Consultoria Legislativa do Senado Federal, 2008. Disponível em: https://www12. senado.leg.br/publicacoes/estudos-legislativos/tipos-de-estudos/textos-para-discussao/td-40-transferenciasintergovernamentais-no-brasil-diagnostico-e-proposta-de-reforma. Acesso em: 24 jun. 2020.

NASCIMENTO, D. E.; SOUZA, M. Valorização do terroir - Uma estratégia de desenvolvimento local. In: LAGES, V.; BRAGA, C.; MORELLI, G. (orgs.). Territórios em movimento: Cultura e identidade como estratégia de inserção competitiva. Brasília: Relume Dumará, 2004, p. 179-196.

PINTO, J. M. R. A política recente de fundos para o financiamento da educação e seus efeitos no pacto federativo. Educação \& Sociedade, Campinas, v. 28, n. 100, p. 877-897, 2007. https://doi.org/10.1590/ S0101-73302007000300012

PINTO, J. M. R. Federalismo, descentralização e planejamento da educação: Desafios aos municípios. Cadernos de Pesquisa, São Paulo, v. 44, p. 624-644, 2014. https://doi.org/10.1590/198053142946

PNUD [PROGRAMA DAS NAÇÕES UNIDAS PARA O DESENVOLVIMENTO]. Human Development Report. New York: Oxford University Press, 2016.

ROWNTREE, D. Statistics without tears: A primer for non-mathematicians. Londres: Penguin, 1981.

SILVA, S. P. Considerações analíticas e operacionais sobre a abordagem territorial em políticas públicas. Políticas Sociais: Acompanhamento e análise, Brasília, Ipea, v. 1, n. 21, p. 89-116, 2013.

\section{Sobre os Autores}

Rafael Encinas é auditor do Tribunal de Contas da União. Mestre em Planejamento e Governança Pública pela Universidade Tecnológica Federal do Paraná (UTFPR), linha de pesquisa "Planejamento e Políticas Públicas". Especializado em Orçamento Público pelo Instituto Serzedello Corrêa (ISC). Graduado em Comunicação Social pela Universidade Federal do Paraná (UFPR).

Rogério Allon Duenhas é professor adjunto da Universidade Tecnológica Federal do Paraná (UTFPR). Mestre e doutor em Desenvolvimento Econômico pela Universidade Federal do Paraná (UFPR). Graduado em Ciências Econômicas pelo Centro Universitário Franciscano do Paraná. Doutorado sanduíche na Newcastle University. Foi pesquisador na Federação das Indústrias do Estado do Paraná.

Recebido: 18 fev. 2019 